ANNOTATIONS

\title{
Drawings of the Fundus
}

The art of pictorial representation of diseased conditions of the fundus dates of course from the year 1851, when Helmholtz gave the ophthalmoscope to the world. The value of these pictures for teaching purposes has long been recognised and from time to time atlases of the fundus have been published: one of the earliest of these was Liebreich's atlas, published in 1863. For many years this held the field, and it is still an extremely good atlas. In 1870 de Wecker and Jaeger brought out their great French atlas; this is now a scarce and valuable book. Frost's Fundus Oculi (1896) was the next milestone; it is a monument of Mr. Head's artistic ability, and we have always considered it as the best all-round atlas of the fundus. Parent's "Atlas d'Ophtalmoscopie" was published in Paris about 30 years ago. The fine plates in Gowers's Medical Ophthalmology deserve mention, and Haab's Atlas, which, from the student's point of view, is a cheap work, well within their means. In Germany, Adam's Ophthalmoskopische Diagnostik came out in 1912, and in the following year Oatman, in America, brought out his Diagnostics of the Fundus Oculi. A good English atlas at a reasonable price was that of Lindsay Johnson and Head, which was published in 1911.

At the present time in England practically the whole of this branch of ophthalmology is in the hands of Theodore Hamblin, Ltd. It is safe to say that the collection of drawings at 15 , Wigmore Street is unique; certainly there is nothing approaching it for completeness in this country, and we much doubt if it can be equalled anywhere else in the world.

We feel that this excellent collection is not so widely known and made use of by ophthalmic surgeons and students as it might be. We have confined our remarks so far to fundus pictures, but Hamblin has an extensive collection of drawings of external diseases as well as lantern slides. As regards these latter it should be known to all that the Adams Frost collection of lantern slides of the drawings in the Fundus Oculi is housed in the Bowman Library and can be borrowed by applying to the Hon. Librarian.

The art of coloured pictures of external conditions has been practised for many years and no better atlas of such conditions can be imagined than Dalrymple's famous atlas of eye pathology.

In our advertisement columns of this month will be found more details of this department of Hamblin's enterprise. We would commend the drawing department at Wigmore Street to our readers. It is open between the hours of 9 a.m. and 6 p.m. Visitors are welcome to inspect the collection; most of the illustrations of 
papers in our journal will be on view together with a series of drawings of similar conditions. The pictures are hung in special frames containing about half a dozen each in a good light. We would wish to express the thanks of the ophthalmic fraternity to Mr. Rayner Batten, who has spent much time in cataloguing and arranging the drawings in this department.

\section{Inaccurate Bibliographies}

To no one does the familiar injunction, "verify your references," apply with more force than to the worker in the scientific field. A paper on a scientific, or even a clinical subject loses much of its value if accompanied by a host of erroneous or unrecognisable references. In this connection it is sad to see the blunders which appear in some European journals, the editors of which appear to take little trouble to check the names and titles submitted by their contributors. We trust that our readers will not jump to the conclusion that THE BRITISH JouRnal OF OPHTHALMOLOGY is immune from error; "humanum est errare," and we plead guilty . to making occasional mistakes. It is in the matter of foreign names that the chief source of error usually lies, and, while it is the duty of the author of a paper to see that the names are correctly spelt in the manuscript (which in the author's own interest should be typewritten), it is incumbent on the editor to correct obvious misprints. It is not fair to the compositor who has to set the type to expect him to be able to read foreign names in the hand-writing of most authors.

These reflections are the outcome of musings on the translation into French of some of the recent work of Stewart Duke-Elder (a serious pitfall these double-barrelled names), every page being headed with the name Stewart. The same journal translates "under the chairmanship of the late Sir Wm. M. Bayliss" as "sous la présidence de feu Sir Wim. M. Baylin." Similarly McCrae becomes Macrac, Orr is Orn, Cramers is Kramer, while Colebrook, Eidinow, and Hill appear as Colebrock, Eidinowd, and Holl, with Hell as an occasional happy variation. The fact that the mistake in the author's name is corrected in the following issue, without apology or explanatory remark, in no way diminishes the confusion which must be felt by the literary searchers.

Another serious inaccuracy in certain foreign journals is to be found in prescriptions of drugs of an unusual type. Any reader who acted on the advice given without verifying the dosage might have serious cause to regret his confidence.

We would plead with the editors of such journals that inaccuracies of the type which we have mentioned are good neither for their reputation nor for science in general. 